\title{
Cellular apoptosis susceptibility (CSE1L/CAS) protein in cancer metastasis and chemotherapeutic drug-induced apoptosis
}

\author{
Cheng-Jeng Tai ${ }^{1}$, Chung-Huei Hsu², Shing-Chuan Shen ${ }^{3}$, Woan-Ruoh Lee ${ }^{3,4}$, Ming-Chung Jiang ${ }^{*}$
}

\begin{abstract}
The cellular apoptosis susceptibility (CSE1L/CAS) protein is highly expressed in cancer, and its expression is positively correlated with high cancer stage, high cancer grade, and worse outcomes of patients. CSE1L (or CAS) regulates chemotherapeutic drug-induced cancer cell apoptosis and may play important roles in mediating the cytotoxicities of chemotherapeutic drugs against cancer cells in cancer chemotherapy. CSE1L was originally regarded as a proliferation-associated protein and was thought to regulate the proliferation of cancer cells in cancer progression. However, the results of experimental studies showed that enhanced CSE1L expression is unable to increase proliferation of cancer cells and CSE1L regulates invasion and metastasis but not proliferation of cancer cells. Recent studies revealed that CSE1L is a secretory protein, and there is a higher prevalence of secretory CSE1L in the sera of patients with metastatic cancer. Therefore, CSE1L may be a useful serological marker for screening, diagnosis and prognosis, assessment of therapeutic responses, and monitoring for recurrence of cancer. In this paper, we review the expression of CSE1L in cancer and discuss why CSE1L regulates the invasion and metastasis rather than the proliferation of cancer.
\end{abstract}

\section{Background}

Cancer is a disease in which a group of cells in the body displays uncontrolled proliferation, invasion, and sometimes metastasis. Malignant cancers are known by their ability to escape from their original location and metastasize to the lymph nodes or other organs. Metastases are the main cause of cancer mortality; therefore diagnoses of metastatic cancer are critical for making therapeutic decisions. Non-metastatic tumors are usually treatable by surgical resection. For patients with cancer that has spread or metastasized, radiation, chemotherapy, or a combination of chemotherapy and radiation can be offered as treatment. Diagnosing cancer metastasis by assaying the level of serological markers of patients is relatively non-invasive. Serum markers that can detect cancer metastasis should be highly useful for screening, diagnosis, prognosis, assessment of therapeutic responses, and monitoring for recurrence of cancer

\footnotetext{
* Correspondence: jiangmwd@gmail.com

'Section of Hematology-Oncology, Department of Medicine, Taipei Medical University and Hospital, Taipei, Taiwan

Full list of author information is available at the end of the article
}

and thus can provide information for taking medical practice to new levels of precision [1,2].

CSE1L/CAS, the cellular apoptosis susceptibility protein, was identified in a studying of an antisense cDNA fragment that is capable of causing MCF-7 human breast cancer cells resistant to apoptosis induced by bacterial toxins such as Pseudomonas exotoxin, diphtheria toxin, and tumor necrosis factor [3]. CSE1L is the human homologue of the yeast chromosome segregation gene, CSE1, and it encodes a 971-amino acid protein with an approximately $100-\mathrm{kDa}$ molecular masses distributing in the cytoplasm and nuclei of cells [4]. CSE1L can associate with microtubules and mitotic spindles, which are cellular organelles for cell mitosis; thus, CSE1L was speculated to play a role in cancer cell proliferation, and was regarded as a proliferation-associated protein in 1996 [5,6]. Since then many pathological reports demonstrated that the expression of CSE1L in cancer is related to cancer proliferation [6-10], although there is no experimental studies to show that increased CSE1L expression in cancer cells can enhance the proliferation of cancer cells. CSE1L is highly expressed in cancer; thus, if CSE1L plays a role in cancer cell 
proliferation during cancer development, increased CSE1L expression in cancer cells should be able to increase the proliferation of cancer cells. Our recent study showed that increased CSE1L expression in MCF7 human breast cancer cells was unable to stimulate cell proliferation [11]. Increased CSE1L expression was also unable to increase the proliferation of other cancer cells including HT-29 human colorectal cancer cells, Hep G2 human hepatocarcinoma cells, 293 kidney cancer cells, and B16-F10 mouse melanoma cells (unpublished data). The results of our study further showed that CSE1L enhanced the invasion and metastasis of B16-F10 cancer cells in animal metastasis studies [11].

CSE1L is a cellular apoptosis susceptibility protein and it is highly expressed in various cancers; our recent studies showed that CSE1L plays an important role in regulating cancer cell apoptosis induced by chemotherapeutic drugs $[12,13]$. Therefore, CSE1L may be a target for developing strategies to improve the efficacy of cancer chemotherapy as well as for screening more potent anticancer reagents.

\section{CSE1L in chemotherapeutic drug-induced cancer cell apoptosis}

Apoptosis (or programmed cell death) plays an important role in mediating apoptotic stimuli including chemotherapeutic drug-induced cell cytotoxicity [14]. CSE1L is a cellular apoptosis susceptibility protein, and CSE1L-mediated cancer cell apoptosis was first investigated by Brinkmann et al. using a vector expressing antisense CSE1L cDNA. Their results showed that CSE1L mediated apoptosis induced by Pseudomonas exotoxin, diphtheria toxin, and tumor necrosis factor but did not mediate apoptosis induced by ricin, cycloheximide, staurosporine, or etoposide, a cancer chemotherapeutic drug. Therefore, CSE1L-mediated apoptosis was thought to be limited to selected apoptotic stimuli such as adenosine diphosphate (ADP)-ribosylating toxins and tumor necrosis factor [3,15]. CSE1L is essential for cell survival, and severe depletion of CSE1L can cause cell death [16]. Those studies used antisense CSE1L cDNA to reduce the cellular CSE1L level; hence the results of their studies might have been a result of those transfected cells expressing not very low levels of CSE1L. Also, they only tested the cancer chemotherapeutic drug, etoposide. An apoptosis-regulating protein should not only regulate apoptosis induced by just ADP-ribosylating toxins and tumor necrosis factor. CSE1L is highly expressed in cancer; therefore enhancing CSE1L expression rather than reducing CSE1L expression in cells is a more appropriate way to study CSE1L-mediated cancer cell apoptosis. We established HT-29 human colorectal cells and MCF-7 breast cancer cells stably transfected with the pcDNA-CSE1L vector, a eukaryotic expression vector carrying the full-length human CSE1L cDNA to study the effect of increased CSE1L expression on cancer cell apoptosis induced by chemotherapeutic drugs $[12,13]$. The chemotherapeutic drugs we tested including paclitaxel, doxorubicin, 5-fluorouracil, cisplatin, etoposide, and 4-OH-tamoxifen. Our results showed that CSE1L regulated cancer cell apoptosis induced by most of the chemotherapeutic drugs that we tested $[12,13]$. Increased CSE1L expression enhanced apoptosis induced by doxorubicin, 5-fluorouracil, cisplatin, and 4-OH-tamoxifen, but decreased apoptosis induced by paclitaxel in HT-29 cancer cells and MCF-7 cancer cells [12,13]. Therefore, CSE1L-mediated apoptosis is not limited to apoptosis induced by ADP-ribosylating toxins and tumor necrosis factor. Microtubules are the target of paclitaxel-induced cancer cell apoptosis [12], thus the expression of microtubule-associated protein may have an impact on cancer cell apoptosis induced by paclitaxel. For example, the expression of the microtubule-associated protein, caveolin-1, was reported to enhance paclitaxel-mediated apoptosis of MCF-7 cells [17]. Low expression level of the microtubule-binding protein, tau, was reported to enhance the sensitivity of human breast cancer to paclitaxel treatment [18]. CSE1L is also a microtubule-associated protein [5]. Paclitaxel treatment can block or prolong cells in the G2/M phase of the cell cycle during apoptosis induction [19], and to induce microtubule aster formation in apoptotic cells [20]. Cell cycle analyses showed that increased CSE1L expression inhibited paclitaxel-induced G2/M phase cell cycle arrest, and immunofluorescence studies showed that increased CSE1L expression inhibited paclitaxel-induced microtubule aster formation in cells [12]. Therefore, CSE1L might inhibit paclitaxel-induced apoptosis by affecting G2/M phase cell cycle arrest and microtubule aster formation induced by paclitaxel.

CPP32 (caspase-3) is one of the central apoptosis executioner molecules, and elevation of cleaved CPP32 is a sign of increased apoptosis [21]. Pathological studies showed that the expression of CPP32 was positively correlated with CSE1L expression in endometrial carcinoma $(p=0.008)$ [22]. Increased CSE1L expression can enhance both interferon- $\gamma$-induced CPP32 expression and the level of the cleaved CPP32 product, thereby inducing apoptosis of HT-29 cancer cells [23]. Therefore, the CPP32 apoptotic pathway is involved in CSE1L-mediated cancer cell apoptosis.

p53 is crucial in mediating cell apoptosis induced by various apoptosis-inducing stimuli, and most chemotherapeutic drugs exert their antitumor activity through a p53-dependent mechanism [24-28]. The activity of $\mathrm{p} 53$ is regulated by both the protein abundance and post-translational modifications of preexisting 
p53 molecules [29,30]. CSE1L was recently shown to associate with a subset of p53 target promoters, and reduced CSE1L expression decreased 53-mediated transcription and thus lowered apoptosis [31]. Our studies showed that increased CSE1L expression can enhance doxorubicin-induced p53 accumulation [12,13]; therefore, CSE1L regulates $\mathrm{p} 53$ protein accumulation induced by chemotherapeutic drugs. Other studies of ours also showed that interferon- $\gamma$ treatment increased CSE1L expression in cancer cells [23] and interferon- $\gamma$ co-treatment enhanced doxorubicin-induced p53 accumulation of Hep G2 hepatoma cells [32]. Thus, interferon- $\gamma$ may increase doxorubicin-induced p53 accumulation by modulating CSE1L expression. CSE1L is highly expressed in cancer, and the results of our studies suggest that CSE1L plays a role in regulating p53 accumulation induced by chemotherapeutic drugs. Therefore, CSE1L may play an important role in mediating the cytotoxicities of chemotherapeutic drugs against cancer cells in cancer chemotherapy. Also, CSE1L may be a target for developing strategies to improve the efficacy and outcomes of cancer chemotherapy.

\section{CSE1L expression in cancer}

CSE1L is highly expressed in various cancer types, and its expression level is positively correlated with high tumor stage, high tumor grade, and worse outcomes of cancer patients. The CSE1L gene is located on chromosome $20 \mathrm{q} 13$, a region frequently harbors amplifications that correlate with cancer aggression [33-35]. The copy number of the CSE1L gene is increased in breast, colon, and bladder cancer cell lines [36]. An array-based comparative genomic hybridization study showed highfrequency amplifications of the CSE1L gene in nasopharyngeal carcinomas [37] and in medulloblastomas [38]. The results of array-based comparative genomic hybridization showed that $57.1 \%$ of the glioblastoma multiforme cases had high-frequency amplification of the CSE1L gene [39]. Idbaih et al. investigated a series of 16 low-grade gliomas and their subsequent progression to higher-grade malignancies using a one-megabase bacterial artificial chromosome (BAC)-based array comparative genomic hybridization technique, and reported that the CSE1L gene was associated with the progression of gliomas [40]. The results of another study using microarray-based detection showed that CSE1L was highly expressed in nasopharyngeal carcinomas [41]. Combined cytogenetic, array-based comparative genomic hybridization studies and expression analyses also showed that CSE1L was significantly overexpressed in advanced prostate cancer xenografts [42].

The results of a pathological study showed that expression of CSE1L was not detected in normal hepatocytes, while strong CSE1L expression was detected in hepatocellular carcinoma [10]. Another study showed that the immunohistochemical staining intensity score of CSE1L was significantly higher in human hepatocellular carcinoma than in non-tumor tissue $(p<0.05)$ [43]. In breast cancer, benign lesions of the breast showed weak CSE1L staining, while $70 \%-90 \%$ of breast tumor cells were heavily stained for CSE1L [9]. In serous ovarian carcinoma, moderate to strong immunostaining of CSE1L was observed in 34 of 41 cases $(83 \%)$ of serous carcinomas, and CSE1L immunoreactivity was positively related to the frequency of apoptotic bodies ( $p=$ $0.0170)$, the tumor grade $(p=0.0107)$, and adverse outcomes $(p=0.0035)$ [44]. Peiro et al. reported that CSE1L protein reactivity was present in $100 \%$ of 69 ovarian carcinomas, and a significant reciprocal correlation was observed between high levels of CSE1L and the histological type, FIGO (International Federation of Obstetrics and Gynecology) stage III and grade 3, residual tumors of $>2 \mathrm{~cm}$, and 20q13.2 (ZNF217 gene) amplification ( $>$ four copies in $>20 \%$ cells) [45]. A tissue array study composed of 244 serous ovarian tumors of different grades (0-3) and stages (I-IV) showed a higher expression of CSE1L in poorly compared to highly differentiated invasive ovarian tumors [46].

An analysis of 89 endometrial carcinomas and 56 samples of non-neoplastic adjacent endometrium showed that CSE1L was expressed in 93\% of endometrial carcinomas neoplastic tissues, while lower levels of CSE1L expression were observed in the adjacent endometrium compared to the carcinomas $(p=0.003)$. Also, CSE1L expression was higher in grade 3 tumors $(p=0.002)$ [22].

Boni et al. studied the expression of CSE1L in 27 control benign and 55 malignant melanocytic lesions (including 32 primary and 23 metastatic lesions), and their results showed that only 13 of the 27 benign melanocytic lesions stained positive for CSE1L [7]. However, 5 of 7 lentigo maligna melanomas, 11 of 12 superficial spreading melanomas, and all acrolentiginous $(n=7)$ and nodular $(n=6)$ melanomas showed medium to high intensity immunoreactivity for CSE1L staining [7]. All metastatic melanomas $(n=23)$ they studied showed strong CSE1L staining [7]. Also, CSE1L detection in clinical stages according to the International Union Against Cancer (UICC) showed an increase from $43 \% \pm$ $34 \%$ CSEL-positive cells in stage I, to $53 \% \pm 26 \%$ in stage II, $68 \% \pm 24 \%$ in stage III, and $72 \% \pm 24 \%$ in stage IV [7].

In normal lymphoid tissue and malignant lymphomas, low-grade non-Hodgkin's lymphoma revealed weak CSE1L staining, with $10 \%$ to $60 \%$ of all cells positive [6]. In contrast, highly malignant non-Hodgkin's lymphoma and malignant cells of Hodgkin's disease displayed very strong CSE1L positivity, with staining of up to $80 \%$ of 
atypical cells [6]. CSE1L was recently shown to be expressed in brain pilocytic astrocytomas [47]. The expression of CSE1L was also reported to be higher in the primary and metastatic human colorectal carcinoma compared to the normal colon mucosa $(p<0.0001)$ [48]. Recent study also showed that the distribution CSE1L in the epithelial glands of neoplastic colorectal epithelium was related to the malignance of colorectal cancer [49].

The pathological studies showed amplification of the CSE1L gene or high expression of CSE1L protein in various cancer types including hepatocellular carcinomas, endometrial carcinomas, cutaneous melanomas, lymphomas, ovarian carcinomas, breast carcinomas, prostate cancers, nasopharyngeal carcinomas, medulloblastomas, glioblastomas, and colorectal carcinomas. The pathological studies also showed that the expression of CSE1L was positively correlated with a higher cancer stage and higher cancer grade, indicating that CSE1L plays an important role in cancer development and progression.

\section{CSE1L is unable to increase cancer cell proliferation}

Cancer cells are characterized by their uncontrolled proliferative abilities. CSE1L is the human homologue of the yeast chromosome segregation gene, CSE1 [4]. Mutation of the yeast CSE1 was shown to lead to defects in both chromosome segregation and B-type cyclin degradation; therefore a role of yeast CSE1 in facilitating the mitotic phase (not the $S$ phase) of yeast replication was described [50,51]. Another study by $\mathrm{Yu}$ et al. reported that depletion of CSE1 resulted in a defect in the S-phase progression of yeast; therefore they demonstrated that CSE1 plays a role in DNA replication during yeast proliferation [52]. It should be noted, however, that their studies were based on CSE1 mutation or depletion and did not include an experiment to see the effect of increased CSE1 expression on yeast replication. Moreover, an immunofluorescence study of the distribution of human CSE1L in cells showed that CSE1L was associated with microtubules and mitotic spindle of mitotic cells; hence CSE1L was first suggested by Scherf et al. to play a role in promoting the mitotic phase of the cell cycle, and thus CSE1L was assumed to be able to increase the proliferation of human cells [5]. Another study by Ogryzko et al. reported that transient transfection of vectors carrying the antisense CSE1L cDNA into HeLa human cervical cancer cells interfered with cell mitosis [53]. Because CSE1L is highly expressed in various cancers, CSE1L was thus regarded as a proliferation-associated protein and was thought to play a role in tumor proliferation during cancer development and progression $[8,54]$. Consequently, many pathological studies reported that the expression of CSE1L was positively correlated with tumor proliferation, and the role of CSE1L in cancer progression was to increase tumor proliferation [6-10], although there are no experimental studies showing that increased CSE1L expression in cancer cells can increase cancer cell proliferation.

We amplified the full-length CSE1L cDNA from human cells and cloned it into the pcDNA3.1 eukaryotic-expressing vector to obtain the pcDNA-CSE1L vector to study the effect of increased CSE1L expression on cancer cell proliferation $[11,55]$. Our results showed that increased CSE1L expression in HT-29 cells did not increase cell proliferation, but on the contrary, increased CSE1L expression decreased the proliferation of HT-29 cells [55]. The HT-29 human colorectal cancer cell line is a special cell line as it easily becomes polarized in culture [56]. The formation of cell polarity is related to cell proliferation, and loss of apical-basal cell polarity can increase cell proliferation [57]. Increased CSE1L expression in HT-29 cells stimulated polarization of HT-29 cells [58]. Hence, we thought that the decrease in cell proliferation of pcDNA-CSE1L vector-transfected HT29 cells might be a result of polarization of HT-29 cells induced by increased CSE1L expression, and not a result of increased CSE1L expression that directly decreased the proliferation of HT-29 cells [55]. Nevertheless, our other studies showed that although increased CSE1L expression was unable to induce polarization of MCF-7 cancer cells as it did in HT-29 cells, enhanced CSE1L expression in MCF-7 cells still decreased but not increased the proliferation of MCF-7 cells [11]. Therefore, CSE1L is unable to stimulate cancer cell proliferation.

CSE1L may be necessary for the $M$ phase cell cycle progression of cells, thus a reduction in the CSE1L level can lead to a defect in chromosome segregation in the mitotic cell-cycle phase. However, it is quite impossible that high expression of CSE1L in cancer cells can enhance chromosome segregation at the mitotic phase of cells and thus increase cancer cell proliferation. First, the key step that determines the rate limitation for cell proliferation is mainly at the G1-S phase of the cell cycle rather than at the M phase [59]. Second, CSE1L is associated with mitotic spindles and functions in the mitotic spindle checkpoint; therefore high expression of CSE1L in cancer cells may halt the progression of mitosis until the cells are truly ready to divide. The p53 protein also plays a role in activating cell-cycle checkpoints, and activation of p53 can stop cell-cycle progression at the cell-cycle checkpoints [60]. The involvement of CSE1L in the proliferation of cancer cells was also supported by a pathological study which reported that the expression of the Ki67 proliferation marker was significantly positively correlated with CSE1L in a study of malignant lymphomas; nevertheless, that study also 
showed that a significant fraction of CSE1L-positive malignant lymphocytes were Ki-67 negative [6]. Various oncogenes may be activated and various anti-oncogenes may be inactivated in tumors; the activated oncogenes and inactivated anti-oncogenes can stimulate the proliferation of cancer cells that highly express CSE1L. Therefore, a positive correlation between CSE1L and Ki67 expression in tumors is insufficient to conclude that CSE1L can stimulate cancer cell proliferation. CSE1L is an apoptosis susceptibility protein; hence increased CSE1L expression can cause cells to be susceptible to apoptosis, let alone to stimulate cell proliferation. In our studies, MCF-7 cells and HT-29 cells transfected with CSE1L-expressing vectors were prone to apoptosis, and exhibited a relatively lower cell growth rate as compared to those of the control vector-transfected cells [11]. Recently, CSE1L was shown to be associated with a subset of p53 target promoters, and reduced CSE1L expression decreased 53-mediated transcription and lowered apoptosis [31]. p53 is known to be able to promote the expression of cell-cycle arrest target genes while enhancing the transactivation of proapoptotic genes [61]. Therefore, that report further suggested that although CSE1L definitely plays an important role in cancer progression, it does not stimulate cancer proliferation. Finally, CSE1L is highly, not barely, expressed in cancer. However, studies reporting that human CSE1L (also yeast CSE1) is associated with cell proliferation were only based on the effect of CSE1L reduction or CSE1 deletion on the growth of human or yeast cells. Therefore, it is inappropriate to use the results of CSE1L reduction experiments to assume that CSE1L can stimulate or increase cancer cell proliferation and draw a conclusion that the role of CSE1L in cancer development is to stimulate cancer proliferation.

\section{CSE1L enhances matrix metalloproteinase- 2 secretion and} increases cancer cell invasion

Increased CSE1L expression is unable to enhance the proliferation of cancer cells, thus CSE1L may promote cancer progression by other mechanisms. A pathological study by Brustmann et al. reported that the immunoreactivity of CSE1L was positively related to high cancer grade $(p=0.0107)$ and adverse outcomes $(p=0.0035)$ in serous ovarian carcinoma [44]. By studying 89 samples of endometrial carcinomas and 56 samples of the non-neoplastic adjacent endometrium, Peiro et al. reported that CSE1L expression was higher in grade 3 tumors $(p=0.002)$, and a shorter survival was observed for patients whose tumors contained $>50 \%$ of CSE1Lpositive cells $(p=0.04)$ [22]. A tissue array study composed of 244 serous tumors of different grades (0-3) and stages (I-IV) showed a higher expression of CSE1L in poorly compared to highly differentiated invasive ovarian tumors [46]. The expression of CSE1L was correlated with advanced stages of melanomas and clinical stages according to the UICC which showed an increase from $43 \% \pm 34 \%$ of CSE1L in stage I, to $53 \% \pm 26 \%$ in stage II, $68 \% \pm 24 \%$ in stage III, and $72 \% \pm 24 \%$ in stage IV [7]. Heavy CSE1L staining was observed in all of the metastatic melanoma $(n=23)$ they studied [7]. The results of these pathological studies indicated that the expression of CSE1L was positively related to high cancer stage and worse outcomes of cancer patients. Metastasis is the main characteristic of high cancer stages and is also the main cause of cancer-related mortality. Therefore, CSE1L may regulate the invasion and metastasis of cancer.

CSE1L can associate with microtubules [4] and the nuclear-transport receptor, importin- $\alpha$ [62]. Hence, CSE1L was predicted to show granule-like staining in the perinuclear areas of cells due to its association with importin- $\alpha$, or show microtubule-like staining due to its association with microtubules in immunofluorescence study. However, in a study of the distribution of CSE1L in cancer cells, we observed that in addition to granulelike staining in cytoplasm surrounding the perinuclear areas, CSE1L also showed vesicle-like staining in the protrusions of MCF-7 cells in immunofluorescence [63]. Cytoplasmic vesicles play important roles in regulating the exocytosis and secretion of cells [64]. The vesiclelike staining of CSE1L in cell protrusions indicates that CSE1L may play a role in regulating cell secretion. The protrusions of cancer cells also play a role in facilitating cancer cell invasion [65]. Furthermore, increased CSE1L expression was shown to increase the secretion of HT29 cells [66]. These results suggest that CSE1L may regulate the secretion and invasion of cancer cells.

Extracellular matrix (ECM) surrounding tumor and ECM-degrading proteases secreted by tumor cells play crucial roles in modulating cancer metastasis [67-69]. Matrix metalloproteinases (MMPs), including MMP-2, are enzymes involved in the degradation of ECM, which show increased expression during cancer metastasis [70-76]. MMP-2 production can be regulated at the level of secretion [77]. Metastatic tumor cells often develop enhanced secretory abilities in order to enhance MMPs secretion, thereby enhancing their metastatic potential [78]. Double-staining immunofluorescence showed that CSE1L regulates the translocation and secretion of MMP-2-containing vesicles [11]. Matrigelbased invasion assays showed that enhanced CSE1L expression increased cell invasion, and reduced CSE1L expression inhibited the invasion of MCF-7 cancer cells [11]. Finally, animal tumor metastasis experiments showed that reduced CSE1L expression decreased the pulmonary metastasis of B16-F10 cells, a highly metastatic cancer cell line, in C57BL/6 mice $[11,79]$. 
Therefore, CSE1L regulates MMP-2 secretion and enhances the invasion of cancer cells.

\section{CSE1L is a secretory protein and there is a higher prevalence of secretory CSE1L in sera of patients with metastatic cancer}

CSE1L is highly expressed in cancer, and its expression level is well correlated with advanced cancer stage and worse patient outcomes. Therefore, CSE1L may play an important role in cancer progression. CSE1L is a microtubule-associated protein [4]. Our recent study showed that the association of CSE1L with microtubules is related with protrusion extension and migration of MCF7 breast cancer cells [80]. In the immunofluorescence study, CSE1L was colocalized with MMP-2 in vesicles surrounding the outside of the MCF-7 cell membranes [Fig 1; also see [63]]. Since MMP-2 is a secretory protein, these results suggest that CSE1L may be secreted together with MMP-2. In immunohistochemistry, positive CSE1L staining was observed in the gland lumen of different cancers including breast cancer and colorectal cancer [63]. The tumor microenvironment, or stroma, consists of ECM and plays an important role in regulating cancer metastasis $[81,82]$. Glands, the major epithelial components of tubular organs, mediate the passage and control of homeostasis by modifying secretion. Glands in cancer tissues also provide the metastatic cancer cells with a route for invasion to adjacent tissues or other organs [83]. Moreover, substances that are secreted from a gland lumen can ultimately reach blood vessels [84]. CSE1L staining in the gland lumen of metastatic cancer tissues indicate that CSE1L may be secreted by cancer tissues and CSE1L may be a secretory protein.

CSE1L as a secretory protein was assessed by immunoblotting with conditioned medium harvested from B16-F10 cancer cells, and the results showed that CSE1L was present in conditioned medium of serumstarved B16-F10 cells [63]. That result confirmed that CSE1L is a secretory protein. Serum samples collected from patients with metastatic cancer were assayed for the presence of secretory CSE1L in sera of patients with metastatic cancer. The results of immunoblotting also showed that secretory CSE1L is present in sera of patients with metastatic cancer [63]. The results of enzyme-linked immunosorbent assay (ELISA) showed that serum CSE1L was detected in 58.2\% (32/55), 32.0\% $(8 / 25)$, and $12.1 \%(8 / 66)$ of patients with metastatic, invasive, and primary cancers, respectively [63]. Serum CSE1L was more prevalent in patients with metastatic cancer. The presence of secretory CSE1L in the sera of patients with metastatic cancer was not restricted to a specific cancer type. Analyses of serum samples from patients with metastatic cancer showed that serum CSE1L was detected in various cancer types including colorectal cancer, breast cancer, lung cancer, cervical cancer, bile duct cancer, esophageal cancer, ovarian cancer, oviduct omental cancer, and head and neck cancer $[63,85]$. Recent study also showed that CSE1L was present in cerebrospinal fluids of patients with intracerebral hemorrhage [86]. Therefore, CSE1L is a secretory protein, and there is a higher prevalence of secretory CSE1L in sera of patients with metastatic cancer.

\section{Phase contrast}

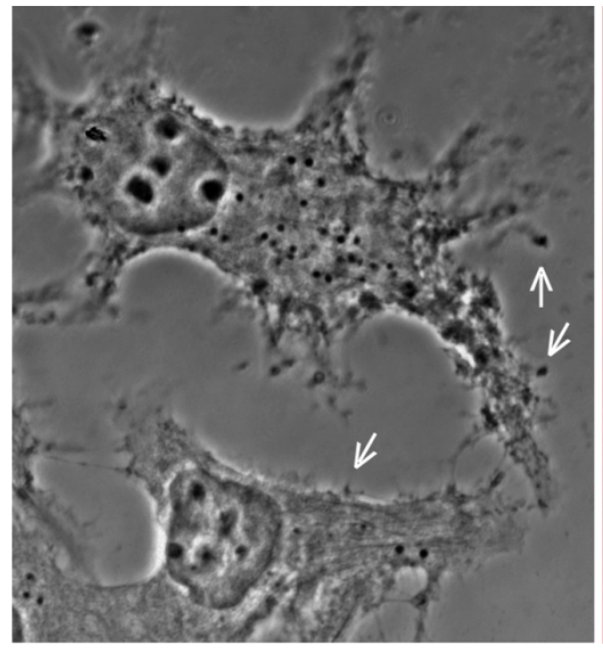

CSE1L

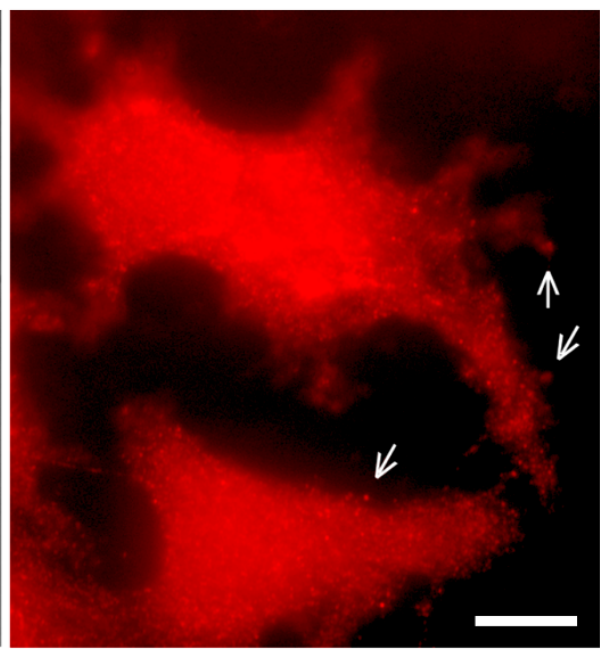

Figure 1 CSE1L staining in vesicles surrounding the outside of cell membrane. The distribution of CSE1L in MCF-7 cells was analyzed by immunohistochemistry with anti-CSE1L antibody. Note the vesicle-like staining of CSE1L in cell protrusions and positive staining of CSE1L in vesicles surrounding the outside of the cell membrane. The scale bar $=30 \mu \mathrm{m}$. The photo is derived from a figure in reference 63 [63]. 


\section{Conclusions}

Metastasis is the main cause of cancer-related mortality; therefore the screening and diagnosis of metastatic cancer are important for cancer treatment [87-95]. CSE1L is highly expressed in various cancers especially high stage cancers, and thus it may play important roles in modulating the development and progression of cancer. CSE1L was previous regarded as a proliferation-associated protein and was thought to be associated with tumor proliferation in cancer progression. Experimental studies showed that increased CSE1L expression in cancer cells was unable to enhance cancer cell proliferation. CSE1L actually is a secretory protein associated with cancer metastasis, and CSE1L is more frequently detected in sera of patients with metastatic cancer than with primary cancer. Therefore, CAS may have clinical utility in metastatic cancer screening and diagnosis, and it may be a potential target for anti-metastasis therapy.

\section{Acknowledgements}

We thank Dr. Ching-Fong Liao, Institute of Cellular and Organismic Biology, Academia Sinica, Taipei, Taiwan, for supporting and cooperation in studying that presented in this article.

\section{Author details}

${ }^{1}$ Section of Hematology-Oncology, Department of Medicine, Taipei Medical University and Hospital, Taipei, Taiwan. ${ }^{2}$ Department of Nuclear Medicine, Taipei Medical University and Hospital, Taipei, Taiwan. ${ }^{3}$ Graduate Institute of Medical Science, Taipei Medical University, Taipei, Taiwan. ${ }^{4}$ Department of Dermatology, Taipei Medical University and Hospital, Taipei, Taiwan.

\section{Authors' contributions}

CJT and MCJ wrote the paper. CHH, SCS, and WR L discussed and participated in paper writing. All authors read and approved the final manuscript.

\section{Competing interests}

The authors declare that they have no competing interests.

Received: 4 March 2010 Accepted: 11 August 2010

Published: 11 August 2010

\section{References}

1. Brenner DE, Normolle DP: Biomarkers for cancer risk, early detection, and prognosis: the validation conundrum. Cancer Epidemiol Biomarkers Prev 2007, 16:1918-1920.

2. Zhang $\mathrm{H}$, Chan DW: Cancer biomarker discovery in plasma using a tissue-targeted proteomic approach. Cancer Epidemiol Biomarkers Prev 2007, 16:1915-1917.

3. Brinkmann U, Brinkmann E, Pastan I: Expression cloning of cDNAs that render cancer cells resistant to Pseudomonas and diphtheria toxin and immunotoxins. Mol Med 1995, 1:206-216.

4. Brinkmann U, Brinkmann E, Gallo M, Pastan I: Cloning and characterization of a cellular apoptosis susceptibility gene, the human homologue to the yeast chromosome segregation gene CSE1. Proc Natl Acad Sci USA 1995, 92:10427-10431.

5. Scherf U, Pastan I, Willingham MC, Brinkmann U: The human CAS protein which is homologous to the CSE1 yeast chromosome segregation gene product is associated with microtubules and mitotic spindle. Proc Natl Acad Sci USA 1996, 93:2670-2674.

6. Wellmann A, Krenacs L, Fest T, Scherf U, Pastan I, Raffeld M, Brinkmann U: Localization of the cell proliferation and apoptosis-associated CAS protein in lymphoid neoplasms. Am J Pathol 1997, 150:25-30.
7. Böni R, Wellmann A, Man YG, Hofbauer G, Brinkmann U: Expression of the proliferation and apoptosis-associated CAS protein in benign and malignant cutaneous melanocytic lesions. Am J Dermatopathol 1999, 21:125-128.

8. Behrens P, Brinkmann U, Wellmann A: CSE1L/CAS: its role in proliferation and apoptosis. Apoptosis 2003, 8:39-44.

9. Behrens P, Brinkmann U, Fogt F: Implication of the proliferation and apoptosis associated CSE1L/CAS gene for breast cancer development. Anticancer Res 2001, 21:2413-2417.

10. Wellmann A, Flemming P, Behrens P, Wuppermann K, Lang H, Oldhafer K, Pastan I, Brinkmann U: High expression of the proliferation and apoptosis associated CSE1L/CAS gene in hepatitis and liver neoplasms: correlation with tumor progression. Int J Mol Med 2001, 7:489-494.

11. Liao CF, Luo SF, Li LT, Lin CY, Chen YC, Jiang MC: CSE1L/CAS, the cellular apoptosis susceptibility protein, enhances invasion and metastasis but not proliferation of cancer cells. J Exp Clin Cancer Res 2008, 27:15.

12. Liao CF, Luo SF, Shen TY, Lin CH, Chien JT, Du SY, Jiang MC: CSE1L/CAS, a microtubule-associated protein, inhibits taxol (paclitaxel)-induced apoptosis but enhances cancer cell apoptosis induced by various chemotherapeutic drugs. BMB Rep 2008, 41:210-216.

13. Liao CF, Luo SF, Tsai CS, Tsao TY, Chen SL, Jiang MC: CAS enhances chemotherapeutic drug-induced p53 accumulation and apoptosis: use of CAS for high-sensitivity anticancer drug screening. Toxicol Mech Methods 2008, 18:771-776.

14. Bursch W, Karwan A, Mayer M, Dornetshuber J, Fröhwein U, SchulteHermann R, Fazi B, Di Sano F, Piredda L, Piacentini M, Petrovski G, Fésüs L, Gerner C: Cell death and autophagy: cytokines, drugs, and nutritional factors. Toxicology 2008, 254:147-157.

15. Brinkmann U, Brinkmann E, Gallo M, Scherf U, Pastan I: Role of CAS, a human homologue to the yeast chromosome segregation gene CSE1, in toxin and tumor necrosis factor mediated apoptosis. Biochemistry 1996, 35:6891-6899.

16. Bera TK, Bera J, Brinkmann U, Tessarollo L, Pastan I: Cse1l is essential for early embryonic growth and development. Mol Cell Biol 2001, 21:7020-7024.

17. Shajahan AN, Wang A, Decker M, Minshall RD, Liu MC, Clarke R: Caveolin-1 tyrosine phosphorylation enhances paclitaxel-mediated cytotoxicity. J Biol Chem 2007, 282:5934-5943.

18. Wagner P, Wang B, Clark E, Lee H, Rouzier R, Pusztai L: Microtubule associated protein (MAP)-tau: a novel mediator of paclitaxel sensitivity in vitro and in vivo. Cell Cycle 2005, 4:1149-1152.

19. Yvon AM, Wadsworth P, Jordan MA: Taxol suppresses dynamics of individual microtubules in living human tumor cells. Mol Biol Cell 1999, 10:947-959.

20. Banerjee S, Fallis AG, Brown DL: Differential effects of taxol on two human cancer cell lines. Oncol Res 1997, 9:237-248.

21. Kumar S: The apoptotic cysteine protease CPP32. Int J Biochem Cell Biol 1997, 29:393-396.

22. Peiró G, Diebold J, Baretton GB, Kimmig R, Löhrs U: Cellular apoptosis susceptibility gene expression in endometrial carcinoma: correlation with $\mathrm{Bcl}-2, \mathrm{Bax}$, and caspase-3 expression and outcome. Int J Gynecol Pathol 2001, 20:359-367.

23. Jiang MC, Lin TL, Lee TL, Huang HT, Lin CL, Liao CF: IRF-1-mediated CAS expression enhances interferon-gamma-induced apoptosis of HT-29 colon adenocarcinoma cells. Mol Cell Biol Res Commun 2001, 4:353-358.

24. Haupt S, Berger M, Goldberg Z, Haupt Y: Apoptosis-the p53 network. J Cell Sci 2003, 116:4077-4085.

25. Wang S, El-Deiry WS: The p53 pathway: targets for the development of novel cancer therapeutics. Cancer Treat Res 2004, 119:175-187.

26. Ling X, Calinski D, Chanan-Khan AA, Zhou M, Li F: Cancer cell sensitivity to bortezomib is associated with survivin expression and p53 status but not cancer cell types. J Exp Clin Cancer Res 2010, 29:8.

27. Cikota BM, Tukić $\sqcup$, Tarabar OT, Magić ZM: Detection of t(14;18), P53 and RAS gene mutations and quantification of residual disease in patients with B-cell non-Hodgkin's lymphoma. J Exp Clin Cancer Res 2007, 26:535-542.

28. Tanaka K, Inoue Y, Hiro J, Yoshiyama S, Toiyama Y, Eguchi T, Miki C, Kusunoki M: Schedule-dependent cytotoxicity of 5-fluorouracil and irinotecan in p53 mutant human colon cancer. J Exp Clin Cancer Res 2007, 26:241-251. 
29. Boehme KA, Blattner C: Regulation of p53-insights into a complex process. Crit Rev Biochem Mol Biol 2009, 44:367-392.

30. Sun L, Zhang G, Li Z, Song T, Huang C, Si L: In GFP with high risk HPV18 E6 fusion protein expressed 293T and MCF-7 cells, the endogenous wild-type p53 could be transiently phosphorylated at multiple sites. J Exp Clin Cancer Res 2008, 27:35.

31. Tanaka T, Ohkubo S, Tatsuno I, Prives C: hCAS/CSE1L associates with chromatin and regulates expression of select p53 target genes. Cell 2007, 130:638-650.

32. Jiang MC, Luo SF, Li LT, Lin CC, Du SY, Lin CY, Hsu YW, Liao CF: Synergic CSE1L/CAS, TNFR-1, and p53 apoptotic pathways in combined interferon- $\gamma /$ adriamycin-induced apoptosis of Hep G2 hepatoma cells. J Exp Clin Cancer Res 2007, 26:91-99.

33. Aust DE, Muders M, Köhler A, Schmidt M, Diebold J, Müller C, Löhrs U Waldman FM, Baretton GB: Prognostic relevance of $20 \mathrm{q} 13$ gains in sporadic colorectal cancers: a FISH analysis. Scand J Gastroenterol 2004, 39:766-772.

34. Aubele $\mathrm{M}$, Werner $\mathrm{M}$, Hofler $\mathrm{H}$ : Genetic alterations in presumptive precursor lesions of breast carcinomas. Anal Cell Pathol 2002, 24:69-76.

35. Nishizaki T, Ozaki S, Harada K, Ito H, Arai H, Beppu T, Sasaki K: Investigation of genetic alterations associated with the grade of astrocytic tumor by comparative genomic hybridization. Gene Chromosome Cancer 1998, 21:340-346.

36. Brinkmann U, Gallo M, Polymeropoulos MH, Pastan I: The human CAS (cellular apoptosis susceptibility) gene mapping on chromosome 20q13 is amplified in BT474 breast cancer cells and part of aberrant chromosomes in breast and colon cancer cell lines. Genome Res 1996, 6:187-194.

37. Hui AB, Lo KW, Teo PM, To KF, Huang DP: Genome wide detection of oncogene amplifications in nasopharyngeal carcinoma by array based comparative genomic hybridization. Int J Oncol 2002, 20:467-473.

38. Tong $\mathrm{CY}$, Hui AB, Yin XL, Pang JC, Zhu XL, Poon WS, Ng HK: Detection of oncogene amplifications in medulloblastomas by comparative genomic hybridization and array-based comparative genomic hybridization. $J$ Neurosurg 2004, 100:187-193.

39. Hui AB, Lo KW, Yin XL, Poon WS, Ng HK: Detection of multiple gene amplifications in glioblastoma multiforme using array-based comparative genomic hybridization. Lab Invest 2001, 81:717-723.

40. Idbaih A, Carvalho Silva R, Crinière E, Marie Y, Carpentier C, Boisselier B, Taillibert S, Rousseau A, Mokhtari K, Ducray F, Thillet J, Sanson M, HoangXuan K, Delattre JY: Genomic changes in progression of low-grade gliomas. J Neurooncol 2008, 90:133-140.

41. Fang WY, Liu TF, Xie WB, Yang XY, Wang S, Ren CP, Deng X, Liu QZ, Huang ZX, Li X, Ding YQ, Yao KT: Reexploring the possible roles of some genes associated with nasopharyngeal carcinoma using microarraybased detection. Acta Biochim Biophys Sin (Shanghai) 2005, 37:541-546.

42. Bar-Shira A, Pinthus JH, Rozovsky U, Goldstein M, Sellers WR, Yaron Y, Eshhar Z, Orr-Urtreger A: Multiple genes in human 20q13 chromosomal region are involved in an advanced prostate cancer xenograft. Cancer Res 2002, 62:6803-6807.

43. Shiraki K, Fujikawa K, Sugimoto K, Ito T, Yamanaka T, Suzuki M, Yoneda K, Sugimoto K, Takase K, Nakano T: Cellular apoptosis susceptibility protein and proliferation in human hepatocellular carcinoma. Int J Mol Med 2006, 18:77-81.

44. Brustmann $\mathrm{H}$ : Expression of cellular apoptosis susceptibility protein in serous ovarian carcinoma: a clinicopathologic and immunohistochemical study. Gynecol Oncol 2004, 92:268-276.

45. Peiro G, Diebold J, Lohrs U: CAS (cellular apoptosis susceptibility) gene expression in ovarian carcinoma: correlation with 20q13.2 copy number and cyclin D1, p53, and Rb protein expression. Am J Clin Pathol 2002, 118:922-929.

46. Ouellet V, Guyot MC, Le Page C, Filali-Mouhim A, Lussier C, Tonin PN, Provencher DM, Mes-Masson AM: Tissue array analysis of expression microarray candidates identifies markers associated with tumor grade and outcome in serous epithelial ovarian cancer. Int J Cancer 2006, 119:599-607.

47. Tung JN, Tsao TY, Tai CJ, Yeh KT, Cheng YW, Jiang MC: Distribution of LAMP-1, LAMP-2, and cathepsin D in eosinophilic granular bodies: possible relationship to cyst development in pilocytic astrocytomas. J Int Med Res.
48. Seiden-Long IM, Brown KR, Shih W, Wigle DA, Radulovich N, Jurisica I, Tsao MS: Transcriptional targets of hepatocyte growth factor signaling and Ki-ras oncogene activation in colorectal cancer. Oncogene 2006, 25:91-102.

49. Uen WC, Tai CJ, Shen SC, Lee WR, Tsao TY, Deng WP, Chiou HY, Hsu CH, Hsieh Cl, Liao CF, Jiang MC: Differential distributions of CSE1L/CAS and E-cadherin in the polarized and non-polarized epithelial glands of neoplastic colorectal epithelium. J Mol Histol.

50. Xiao Z, McGrew JT, Schroeder AJ, Fitzgerald-Hayes M: CSE1 and CSE2, two new genes required for accurate mitotic chromosome segregation in Saccharomyces cerevisiae. Mol Cell Biol 1993, 13:4691-4702.

51. Irniger S, Piatti S, Michaelis C, Nasmyth K: Genes involved in sister chromatid separation are needed for B-type cyclin proteolysis in budding yeast. Cell 1995, 81:269-278.

52. Yu L, Peña Castillo L, Mnaimneh S, Hughes TR, Brown GW: A survey of essential gene function in the yeast cell division cycle. Mol Biol Cell 2006, 17:4736-4747.

53. Ogryzko W, Brinkmann E, Howard BH, Pastan I, Brinkmann U: Antisense inhibition of CAS, the human homologue of the yeast chromosome segregation gene CSE1, interferes with mitosis in HeLa cells. Biochemistry 1997, 36:9493-9500.

54. Brinkmann U: CAS, the human homologue of the yeast chromosomesegregation gene CSE1, in proliferation, apoptosis, and cancer. Am J Hum Genet 1998, 62:509-513.

55. Jiang MC, Liao CF: CSE1/CAS overexpression inhibits the tumorigenicity of HT-29 colon cancer cells. J Exp Clin Cancer Res 2004, 23:325-332.

56. Le Bivic A, Hirn M, Reggio H: HT-29 cells are an in vitro model for the generation of cell polarity in epithelia during embryonic differentiation. Proc Natl Acad Sci USA 1988, 85:136-140.

57. Wodarz A: Tumor suppressors: linking cell polarity and growth control. Curr Biol 2000, 10:624-626.

58. Jiang MC, Liao CF, Tai CC: CAS/CSE 1 stimulates E-cadhrin-dependent cell polarity in HT-29 human colon epithelial cells. Biochem Biophys Res Commun 2002, 294:900-905.

59. Moeller SJ, Sheaff RJ: G1 phase: components, conundrums, context. Results Probl Cell Differ 2006, 42:1-29.

60. Giono LE, Manfredi JJ: The p53 tumor suppressor participates in multiple cell cycle checkpoints. J Cell Physiol 2006, 209:13-20.

61. Boehme KA, Blattner C: Regulation of p53-insights into a complex process. Crit Rev Biochem Mol Biol 2009, 44:367-392.

62. Kutay U, Bischoff FR, Kostka S, Kraft R, Görlich D: Export of importin alpha from the nucleus is mediated by a specific nuclear transport factor. Cell 1997, 90:1061-1071.

63. Tung MC, Tsai CS, Tung JN, Tsao TY, Chen HC, Yeh KT, Liao CF, Jiang MC: Higher prevalence of secretory CSE1L/CAS in sera of patients with metastatic cancer. Cancer Epidemiol Biomarkers Prev 2009, 18:1570-1577.

64. Pickett JA, Edwardson JM: Compound exocytosis: mechanisms and functional significance. Traffic 2006, 7:109-116.

65. Ayala I, Baldassarre M, Caldieri G, Buccione R: Invadopodia: a guided tour. Eur J Cell Biol 2006, 85:159-164.

66. Tsao TY, Tsai CS, Tung JN, Chen SL, Yue CH, Liao CF, Wang CC, Jiang MC: Function of CSE1L/CAS in the secretion of HT-29 human colorectal cells and its expression in human colon. Mol Cell Biochem 2009, 327:163-170.

67. DeClerck YA, Mercurio AM, Stack MS, Chapman HA, Zutter MM, Muschel RJ, Raz A, Matrisian LM, Sloane BF, Noel A, Hendrix MJ, Coussens L, Padarathsingh M: Proteases, extracellular matrix, and cancer: a workshop of the path B study section. Am J Pathol 2004, 164:1131-1139.

68. Tsanou E, loachim E, Briasoulis E, Charchanti A, Damala K, Karavasilis V, Pavlidis N, Agnantis NJ: Clinicopathological study of the expression of syndecan-1 in invasive breast carcinomas. correlation with extracellular matrix components. J Exp Clin Cancer Res 2004, 23:641-650.

69. Ban S, Goto Y, Mitsuki N, Kamada K, Fujita T, Takahama M: Change in cytoskeletal phenotype and extracellular matrix production of muscularis mucosae during early invasive colorectal adenocarcinoma. J Exp Clin Cancer Res 2002, 21:401-407.

70. Zhang Y, Wang C, Mizukami H, Itoh H, Kusama M, Ozawa K, Jinbu Y: Increased expression and activation of matrix metalloproteinase-2 (MMP-2) in O-1N: hamster oral squamous cell carcinoma with high potential lymph node metastasis. J Exp Clin Cancer Res 2006, 25:417-423. 
71. Rodríguez-Salvador J, Armas-Pineda C, Perezpeña-Diazconti M, Chico-Ponce de León F, Sosa-Sáinz G, Lezama P, Recillas-Targa F, Arenas-Huertero F: Effect of sodium butyrate on pro-matrix metalloproteinase- 9 and -2 differential secretion in pediatric tumors and cell lines. J Exp Clin Cancer Res 2005, 24:463-473.

72. Przybylowska K, Zielinska J, Zadrozny M, Krawczyk T, Kulig A, Wozniak P, Rykala J, Kolacinska A, Morawiec Z, Drzewoski J, Blasiak J: An association between the matrix metalloproteinase 1 promoter gene polymorphism and lymphnode metastasis in breast cancer. J Exp Clin Cancer Res 2004, 23:121-125.

73. Ishii $Y$, Nakasato $Y$, Kobayashi S, Yamazaki Y, Aoki T: A study on angiogenesis-related matrix metalloproteinase networks in primary hepatocellular carcinoma. J Exp Clin Cancer Res 2003, 22:461-470.

74. Szyllo K, Smolarz B, Romanowicz-Makowska H, Niewiadomski M, Kozlowska E, Kulig A: The promoter polymorphism of the matrix metalloproteinase 3 (MMP-3) gene in women with ovarian cancer. J Exp Clin Cancer Res 2002, 21:357-361.

75. Matsuoka T, Yashiro M, Sawada T, Ishikawa T, Ohira M, Hirakawa K, Chung YS: Effect of a matrix metalloproteinase inhibitor on a lymph node metastatic model of gastric cancer cells passaged by orthotopic implantation. J Exp Clin Cancer Res 2001, 20:213-218.

76. Tsai CS, Luo SF, Ning CC, Lin CL, Jiang MC, Liao CF: Acetylsalicylic acid regulates MMP-2 activity and inhibits colorectal invasion of murine B16F0 melanoma cells in C57BL/6J mice: effects of prostaglandin F2 $\alpha$. Biomed Pharmacother 2009, 63:522-527.

77. Ben-Yosef Y, Lahat N, Shapiro S, Bitterman H, Miller A: Regulation of endothelial matrix metalloproteinase- 2 by hypoxia/reoxygenation. Circ Res 2002, 90:784-791.

78. Moser TL, Young TN, Rodriguez GC, Pizzo SV, Bast RC Jr, Stack MS: Secretion of extracellular matrix-degrading proteinases is increased in epithelial ovarian carcinoma. Int J Cancer 1994, 56:552-559.

79. Yoshiura K, Nishishita T, Nakaoka T, Yamashita N, Yamashita N: Inhibition of B16 melanoma growth and metastasis in C57BL mice by vaccination with a syngeneic endothelial cell line. J Exp Clin Cancer Res 2009, 28:13.

80. Tai CJ, Shen SC, Lee WR, Liao CF, Deng WP, Chiou HY, Hsieh Cl, Tung JN, Chen CS, Chiou JF, Li LT, Lin CY, Hsu CH, MC Jiang: Increased cellular apoptosis susceptibility (CSE1L/CAS) protein expression promotes protrusion extension and enhances migration of MCF-7 breast cancer cells. Exp Cell Res

81. Zigrino $P$, Löffek S, Mauch C: Tumor-stroma interactions: their role in the control of tumor cell invasion. Biochimie 2005, 87:321-328.

82. Hara $Y$, Ogata $Y$, Shirouzu K: Early tumor growth in metastatic organs influenced by the microenvironment is an important factor which provides organ specificity of colon cancer metastasis. J Exp Clin Cancer Res 2000, 19:497-504

83. Cedermark BJ, Blumenson LE, Pickren JW, Holyoke DE, Elias EG: The significance of metastases to the adrenal glands in adenocarcinoma of the colon and rectum. Surg Gynecol Obstet 1977, 144:537-546.

84. Pieper-Bigelow C, Strocchi A, Levitt MD: Where does serum amylase come from and where does it go? Gastroenterol Clin North Am 1990, 19:793-810.

85. Tsai CS, Chen HC, Tung JN, Tsou SS, Tsao TY, Liao CF, Chen YC, Yeh CY, Yeh KT, Jiang MC: Serum CSE1L/CAS protein is a potential prognostic marker for metastatic colorectal cancer. Am J Pathol 2010, 176:1619-1628.

86. Tung JN, Tsao TY, Chen SL, Tai CJ, Shen SC, Cheng YW, Jiang MC: Presence of secretory cellular apoptosis susceptibility protein in cerebrospinal fluids of patients with intracerebral hemorrhage caused by stroke and neurotrauma. Neuro Endocrinol Lett 2010, 31:390-398.

87. Wu L, Peng CW, Hou JX, Zhang YH, Chen C, Chen LD, Li Y: Coronin-1C is a novel biomarker for hepatocellular carcinoma invasive progression identified by proteomics analysis and clinical validation. $J$ Exp Clin Cancer Res 2010, 29:17.

88. Liu Y, Ji R, Li J, Gu Q, Zhao X, Sun T, Wang J, Li J, Du Q, Sun B: Correlation effect of EGFR and CXCR4 and CCR7 chemokine receptors in predicting breast cancer metastasis and prognosis. J Exp Clin Cancer Res 2010, 29:16.

89. Lu Y, Lu P, Zhu Z, Xu H, Zhu X: Loss of imprinting of insulin-like growth factor 2 is associated with increased risk of lymph node metastasis and gastric corpus cancer. J Exp Clin Cancer Res 2009, 28:125

90. Yu H, Zhang S, Zhang R, Zhang L: The role of VEGF-C/D and Flt-4 in the lymphatic metastasis of early-stage invasive cervical carcinoma. J Exp Clin Cancer Res 2009, 28:98.
91. Appetecchia M, Meçule A, Ducci M, Palma L, Castelli M: Serum cytokeratins determination in differentiated thyroid carcinoma. J Exp Clin Cancer Res 2001, 20:253-256.

92. Yoshiura K, Nishishita T, Nakaoka T, Yamashita N, Yamashita N: Inhibition of B16 melanoma growth and metastasis in C57BL mice by vaccination with a syngeneic endothelial cell line. J Exp Clin Cancer Res 2009, 28:13.

93. Shi H, Gu Y, Yang J, Xu L, Mi W, Yu W: Lipocalin 2 promotes lung metastasis of murine breast cancer cells. J Exp Clin Cancer Res 2008, 27:83.

94. Peng XC, Yang L, Yang LP, Mao YQ, Yang HS, Liu JY, Zhang DM, Chen L, Wei YQ: Efficient inhibition of murine breast cancer growth and metastasis by gene transferred mouse survivin Thr34- > Ala mutant. J Exp Clin Cancer Res 2008, 27:46.

95. Radulescu RT: Oncoprotein metastasis and its suppression revisited. J Exp Clin Cancer Res 2010, 29:30.

\section{doi:10.1186/1756-9966-29-110}

Cite this article as: Tai et al:: Cellular apoptosis susceptibility (CSE1L/

CAS) protein in cancer metastasis and chemotherapeutic drug-induced apoptosis. Journal of Experimental \& Clinical Cancer Research 2010 29:110.

\section{Submit your next manuscript to BioMed Central and take full advantage of:}

- Convenient online submission

- Thorough peer review

- No space constraints or color figure charges

- Immediate publication on acceptance

- Inclusion in PubMed, CAS, Scopus and Google Scholar

- Research which is freely available for redistribution

Submit your manuscript at www.biomedcentral.com/submit
C) Biomed Central 